\title{
Modelling The Effects of Aggregate Size on Alkali Aggregate Reaction Expansion
}

\author{
Nawal Zahira Sekrane \\ Civil Engineering and Environment Laboratory \\ Djillali Liabes University of Sidi Bel Abbes \\ Sidi Bel Abbés 22000, Algeria \\ n.sekrane@gmail.com
}

\author{
Aissa Asroun \\ Civil Engineering and Environment Laboratory \\ Djillali Liabes University of Sidi Bel Abbes \\ Sidi Bel Abbés 22000, Algeria \\ a_asroun@yahoo.fr
}

\begin{abstract}
This work aims at developing models to predict the potential expansion of concrete containing alkali-reactive aggregates. The paper gives measurements in order to provide experimental data concerning the effect of particle size of an alkali-reactive siliceous limestone on mortar expansion. Results show that no expansion was measured on the mortars using small particles $(0.5-1.0 \mathrm{~mm})$ while the particles $(1.0-2.0 \mathrm{~mm})$ gave the largest expansions $(0.217 \%)$. Two models are proposed, the first one studies the correlations between the measured expansions and the size of aggregates, the second one calculates the thickness of the porous zone necessary to take again all the volume of the gel created.
\end{abstract}

Keywords-Alkali aggregate reaction; expansion; particle size; model; porous zone.

\section{INTRODUCTION}

Alkali aggregate reaction (AAR) affects numerous civil engineering structures and causes irreversible expansion and cracking. AAR is a chemical reaction between the reactive siliceous phases of aggregates and alkalis of the cement. The product of the reaction (gel) leads to the apparition of a swelling pressure causing expansion and cracking. The consequences are a decrease in the functional capacities of civil engineering structures such as hydraulic dams.

The gel volume formed by the chemical reaction can be used as input data to structural models [1]. One of the main difficulties is to assess the volume of this gel [2]. Microscopic models [3-5] could be one method of doing this. Such models should be able to predict the differences of expansions with the variation of all influential parameters such as the aggregate size and should be compared with experimental results. Several papers deal with the effect of particle size of reactive aggregates on the expansion due to AAR. Experiments have been performed on different types of aggregates. It seems that the highest AAR-expansion caused by the effect of the particle size of the reactive aggregate depends on the composition of the aggregate itself [6-10].

Our work aims to study the effect of size for reactive siliceous Limestone; this type of aggregate has been used in many structures. Therefore, in order to test models to predict the potential expansion of concrete containing such alkali reactive aggregates, tests have been performed to provide experimental data on the effect of particle size on mortar expansion. This paper presents the experimental results and gives the data necessary for model development. Three mixdesigns were studied containing one reactive size distribution (0.5-1.0 mm, $1.0-2.0 \mathrm{~mm}$ or $2.0-4.0 \mathrm{~mm}$ ). First, the paper presents the experimental conditions of the tests; then, the measurements of AAR-expansions are presented. Finally, a model is proposed to analyze the experimental results by studying the correlations between the measured expansions and the size of aggregates. Another model is presented, which calculates the thickness of the porous zone necessary to take again all the volume of the gel.

\section{EXPERIMENTAL CONDITIONS}

\section{A. Materials}

The cement used to carry out these tests was a CEM I 42.5 Portland cement which contains a rate of alkaline equivalent $\left(\mathrm{Na}_{2} \mathrm{O}_{\text {eq }}\right) \leq 0.6 \%$, it has a Blaine specific area of 3585 $\mathrm{cm}^{2} / \mathrm{g}$ and a density of 3.2. The chemical and mineralogical composition according to Bogue formulas are given in Tables I and II respectively. A water to cement ratio of 0.45 was used. The aggregate used was the sand of the careers whose bed rock is a siliceous limestone which is an alkali-reactive rock. It is crushed and sieved to the following three size ranges: 0.5-1.0 $\mathrm{mm}, 1.0-2.0 \mathrm{~mm}$ and $2.0-4.0 \mathrm{~mm}$ with sand to cement ratio of 2.25. The chemical composition of the aggregate is given in Tables III.

TABLE I. CHEMICAL COMPOSITION OF THE CEMENT.

\begin{tabular}{|c|c|}
\hline Oxide & \% \\
\hline $\mathrm{SiO}_{2}$ & 22.07 \\
\hline $\mathrm{CaO}$ & 63.83 \\
\hline $\mathrm{Al}_{2} \mathrm{O}_{3}$ & 6.41 \\
\hline $\mathrm{Fe}_{2} \mathrm{O}_{3}$ & 4.16 \\
\hline $\mathrm{MgO}$ & 0.21 \\
\hline $\mathrm{SO}_{3}$ & 1.49 \\
\hline $\mathrm{P} . \mathrm{F}$ & 1.73 \\
\hline $\mathrm{Na}_{2} \mathrm{Oeq}$ & 0.60 \\
\hline Free CaO & 0.16 \\
\hline
\end{tabular}


TABLE II. MINERALOGICAL COMPOSITION OF THE CEMENT ACCORDING TO BOGUE.

\begin{tabular}{|c|c|}
\hline Minerals & \% \\
\hline C3S & 38.09 \\
\hline C2S & 34.62 \\
\hline C3A & 9.95 \\
\hline C4AF & 12.65 \\
\hline
\end{tabular}

TABLE III. CHEMICAL COMPOSITION OF THE AGGREGATE.

\begin{tabular}{|c|c|}
\hline Oxide & \% \\
\hline $\mathrm{SiO}_{2}$ & 5.92 \\
\hline $\mathrm{CaO}$ & 47.10 \\
\hline $\mathrm{Al}_{2} \mathrm{O}_{3}$ & 3.32 \\
\hline $\mathrm{Fe}_{2} \mathrm{O}_{3}$ & 0.99 \\
\hline $\mathrm{MgO}$ & 0.85 \\
\hline $\mathrm{SO}_{3}$ & 0.89 \\
\hline $\mathrm{P.F}$ & 39.29 \\
\hline
\end{tabular}

To prepare the soda solution, the pastilles of sodium hydroxide $(\mathrm{NaOH})$ were dissolved in distilled water. The mix designs are reported in the Table IV.

TABLE IV. THE QUANTITIES USED FOR MORTAR.

\begin{tabular}{|c|c|}
\hline Material & mortar batch \\
\hline Cement & $800 \mathrm{~g}$ \\
\hline Aggregate & $1800 \mathrm{~g}$ \\
\hline Water & $360 \mathrm{ml}$ \\
\hline Sodium hydroxide & $40 \mathrm{~g} / \mathrm{l}$ \\
\hline
\end{tabular}

\section{B. Mixing and moulding procedure}

For each test a mould of three prismatic samples of 40x40x160 mm was used. All samples were cast using the following protocol [11-12]: Cement was mixed with water in the mixer at slow speed for $30 \mathrm{~s}$; after, aggregate was added to the mix; Mixing was continued for $30 \mathrm{~s}$ at high speed. Molds were filled on two stages by carrying out 60 shocks after each stage using the table with shock. The bars were covered with plastic sheet and placed in a sealed container containing water. After $24 \mathrm{~h}$, all samples were demolded and their initial length measurement were taken by the difrometer which is equipped with a comparator making it possible to carry out measurements with an exactitude less than or equal to 0.005 $\mathrm{mm}$. Each measurement was the mean of the values of the three samples. The bars were immersed in water in sealed containers which were then placed in an oven at $80^{\circ} \mathrm{C}$ for $24 \mathrm{~h}$; then they were transferred in containers filled with a $1 \mathrm{M} \mathrm{NaOH}$ solution during 14 days in the oven at $80^{\circ} \mathrm{C}$. The length changes of the bars were measured at 3, 5, 7, 10, 12 and 14 days, respectively.

\section{EXPERIMENTAL RESULTS AND DISCUSSION}

The expansions for bars with a single fraction of reactive aggregate were obtained by subtracting the initial length of the samples taken at the time of the demolding from the final length at time $(\mathrm{t})$. The relative variation length was given by the following formula:

$$
\varepsilon_{i}=\frac{L_{1 i}-L_{0 i}}{L}
$$

With

$\varepsilon_{i}$ : Relative deformation of sample $i \quad(i=1,2,3)$.

$L_{0 i}$ : The initial length of sample $i(i=1,2,3)$.

$L_{1 i}$ : The final length of sample $i(i=1,2,3)$.

The expansion $\varepsilon$ was obtained by the mean of the $\varepsilon_{i}$.

Expansion results for samples are reported in Figure 1, a similar shape of expansion curve is observed and it is indicated that the expansion of bars basically increases with time. For the same content of reactive particles, the expansion was smaller for the $0.5-1.0 \mathrm{~mm}$ reactive particles than for the $1.0-2.0 \mathrm{~mm}$ and $2.0-4.0 \mathrm{~mm}$ reactive ones. Using $0.10 \%$ as criteria for expansion, the bars with $0.5-1.0 \mathrm{~mm}$ aggregate particles showed AAR-expansion lower than about $(0.045 \%)$. It clearly indicates that, the bars with $1.0-2.0 \mathrm{~mm}$ size fraction gave the largest expansion (0.217\%), for bars with 2.0-4.0 mm aggregate particles AAR-expansion measured is (0.148\%).

Figure 2 and Figure 3 shows the kinetics of the AARexpansion measured for 14 days. For this reactive siliceous limestone, no AAR- expansion was measured for small reactive particles (less than $1.0 \mathrm{~mm}$ ). AAR-expansion appeared for particles having diameters greater than $1.0 \mathrm{~mm}$. The critical particle size that caused AAR-expansion was around $1.25 \mathrm{~mm}$ and $1.75 \mathrm{~mm}$. AAR-expansion increased with the size of reactive particles between 0 and $1.75 \mathrm{~mm}$. Finally, the larger reactive particles (2.0-4.0 mm) showed lower expansions.

\section{MODEL AND DISCUSSION}

The models presented in this section aim to improve the understanding of the experimental results obtained in the first part. The first model calculates the asymptotic expansion of mortars containing only one size [13], the second model calculates the distance in which the gel must diffuse in the paste to be completely adapted by the porosity [14]. Finally, it should be noted that the fitted parameters supplied here are only applicable for the aggregate studied in this paper.

The various assumptions constitutive of the models are (Figure 4):

- $\quad$ The siliceous aggregates are spherical of diameter $D_{i}$;

- A volume of silica produced “ $n$ ” volume of gel $(n>1)$;

- The small and coarse aggregates are attacked on an identical thickness " $x$ ";

- There exists a porous zone of thickness " $t$ " surrounding the aggregates in which the products are formed;

- The layer of the gel surrounding the aggregates is fine in comparison with the diameter of the aggregates and its thickness is uniform.

The reactional mechanisms selected are inspired by those evoked in [15-17]. The ions (alkaline, ions hydroxyls and 
calcium) penetrate in the reactive aggregates by diffusion. The siliceous system is attacked by the ions hydroxyls. The created negative charges are balanced by the alkaline ones and the ions calcium to form silico-alkaline products (gel) or silico-calcic. These products are formed in a zone of porosity surrounding the reactive aggregates. When the volume of the products becomes larger than porous volume available, the concrete starts to swell [18].

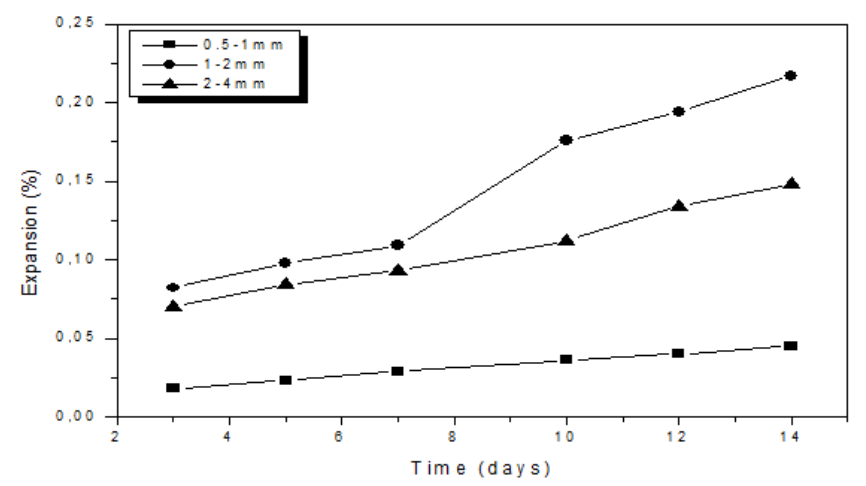

Fig. 1. Expansions of mortars with a single reactive fraction as a function of time.

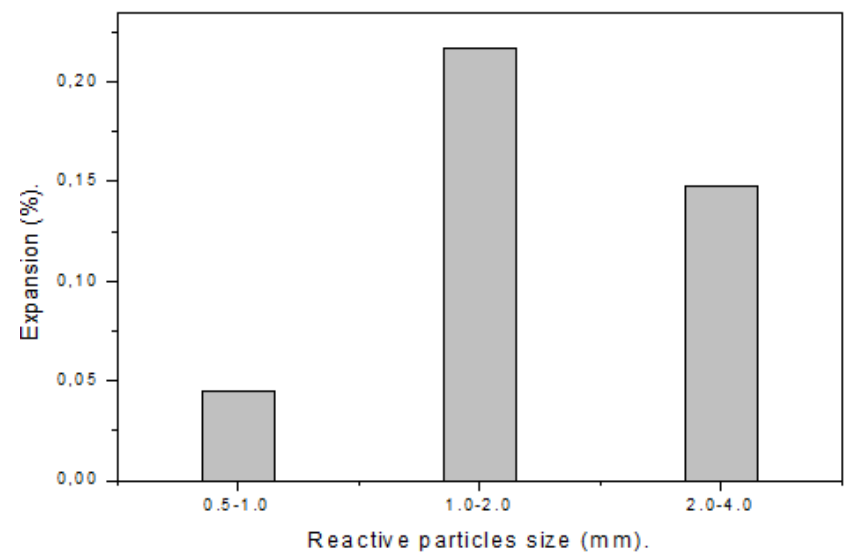

Fig. 2. Expansions of mortars containing reactive particles of size (0.5 1.0) mm, (1.0 - 2.0) mm, (2.0 - 4.0) mm measured at 14 days.

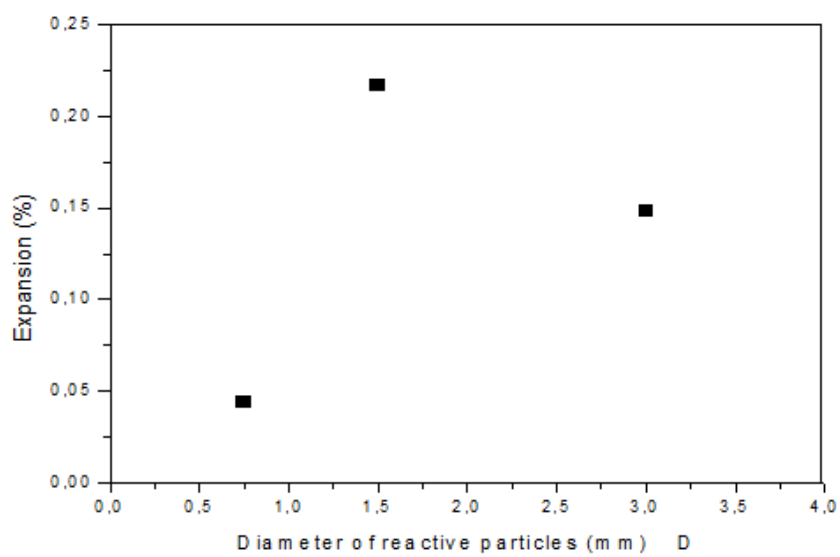

Fig. 3. Relationship between expansion and reactive particles size.
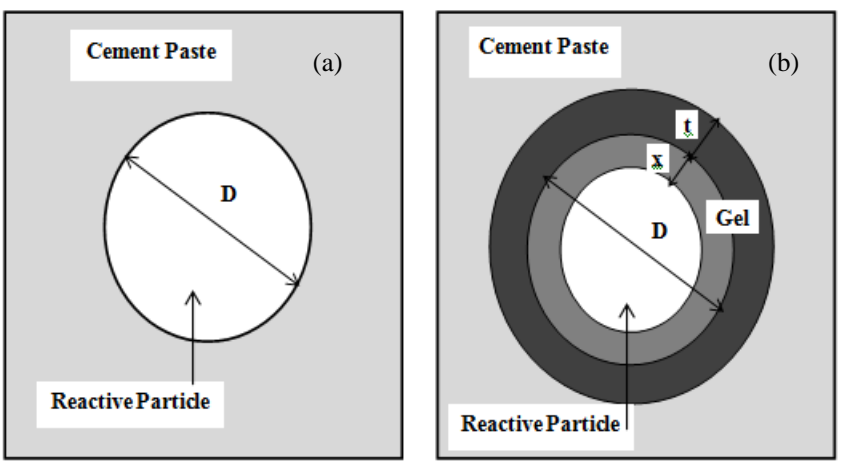

Fig. 4. Schematic of a reactive aggregate: (a) before the reaction and (b) after the reaction.

\section{A. Asymptotic expansion model}

The expansion of the mortar is caused by the expansions of the AAR-gels. It can be assumed that this expansion is caused by the volume variation of the aggregate (in the presence of gel). For the sake of simplicity, it is assumed that the mortar expansion due to AAR ( $\varepsilon_{A A R}$ ) is proportional to the aggregate expansion (2). For several sizes of reactive particles, the aggregate expansion is the sum of the expansions of all the reactive aggregates [13].

$$
\varepsilon_{\text {AAR }}=k \cdot \sum_{i=1}^{N} \phi_{i} \varepsilon_{i}
$$

where:

$\varepsilon_{i}$ : The expansion of one reactive aggregate of class $i$.

$\phi_{i}$ : The volume fraction of reactive aggregates of class $i$ relative to the mortar volume (total volume of reactive aggregate of class $i$ / total volume of the mortar).

$N$ : The number of classes of reactive aggregates.

$K$ : The fraction of expansion due to AAR related to the expansion of reactive aggregates.

During the reaction, at a given moment, the aggregate is attacked on a thickness " $x$ " and it produces a volume of the gel equal to $V_{i}^{g}$ :

$$
V_{i}^{g}=n \cdot\left[\frac{\pi D_{i}^{3}}{6}-\frac{\pi\left(D_{i}-2 x\right)^{3}}{6}\right]
$$

During the formation of the AAR-gel, a part of the gel can migrate through the porosity close to the aggregate. Therefore, the aggregate expansion for one aggregate $i$ can be described by (4).

$$
\varepsilon_{i}=\frac{\left\langle V_{i}^{g}-V_{i}^{p}\right\rangle^{+}}{V_{i}}
$$

with: 
$V_{i}^{p}$ : The volume of the porosity close to the reactive aggregate in which the AAR-gel can migrate without causing expansion.

$V_{i}$ : The volume of one reactive particle, it is given by the following formula:

$$
V_{i}=\frac{\pi D_{i}}{6}
$$

where:

$D_{i}$ : The diameter of the reactive particle.

$\langle X\rangle^{+}$: The positive part of $X$,

If: $\left\{\begin{array}{l}X<0,\langle X\rangle^{+}=0 \\ X>0,\langle X\rangle^{+}=X\end{array}\right.$

Assuming that the gel can migrate along the same distance of the aggregate " $t$ " whatever the size of the aggregate (simplifying hypothesis), the volume of the porosity is given by (6):

$$
V_{i}^{p}=\left[\frac{\pi\left(D_{i}+2 t\right)^{3}}{6}-\frac{\pi D_{i}^{3}}{6}\right] . P
$$

where:

$P$ : is the porosity of the mortar.

The combination of (2)-(6) for only one class of reactive particles leads to the (7).

$$
\varepsilon_{A A R}=k \cdot \phi_{i} \cdot\left[\left\langle n \cdot\left(1-\frac{\left(D_{i}-2 x\right)^{3}}{D_{i}^{3}}\right)-P \cdot\left(\frac{\left(D_{i}+2 t\right)^{3}}{D_{i}^{3}}-1\right)\right\rangle^{+}\right]
$$

In order to carry out this calculation and in order to obtain a linear expansion (comparable to the measured expansion on mortars), the porosity of the mortar ( $P$ ), the thickness of attack of the aggregates $(x)$, the voluminal coefficient of the gel $(n)$ and the distance $(t)$ which gel must diffuse in the cement paste are fixed. These calculations are performed using Maple 12. The calculated expansions are plotted in Figure 5. These results are similar to the experiments results. It is shown that the bars with 0.5-1.0 mm size fraction showed AAR-expansion equal to $0.031 \%$, the bars with $1.0-2.0 \mathrm{~mm}$ size fraction gave the largest expansion $(0.227 \%)$ and the bars with $2.0-4.0 \mathrm{~mm}$ size fraction gave expansion equal to $0.167 \%$.

Figure 6 compares experiment results of AAR-expansion of mortars containing one size of reactive particles with the results calculated by the asymptotic expansion model; they have a similar shape of expansion curve. It is observed that the model represents the experimental data well.
To sum up, the model developed in this section assumes that the increase of AAR-expansion with the size of reactive particles can be explained by the effect of the porosity connected to the reactive aggregate. The volume of gel was calculated according to (3) and the volume of porosity to be filled around each particle of diameter $D_{i}$ before the expansion starts is given by (6). The expansion of mortar was then taken as the volumetric change of the aggregate due to the gel volume not contained in the porous zone (4). This simple relation allows the final expansion to be plotted against the reactive aggregate. The small reactive particles, because of their uniform distribution in the paste, could create gel distributed regularly in all the mortar. This gel would migrate in the matrix and to be easily adapted by the porosity of the cement paste, without creating expansion of the mortar. But, the gel produced around the coarse grains could generate considerable pressures leading to important macroscopic swellings if the thickness of porosity was little.

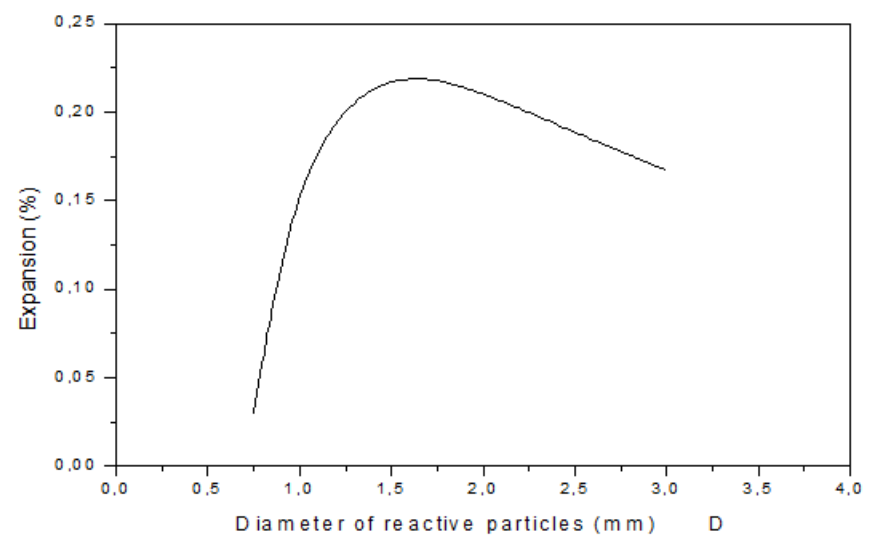

Fig. 5. Expansion of the mortars against the diameter ( $D_{i}$ ) of the reactive particles: calculated by the asymptotic expansion model $(\mathrm{K}=0.1$, $\mathrm{n}=2.5, \mathrm{x}=0.25, \mathrm{t}=0.7, \mathrm{P}=10 \%)$.

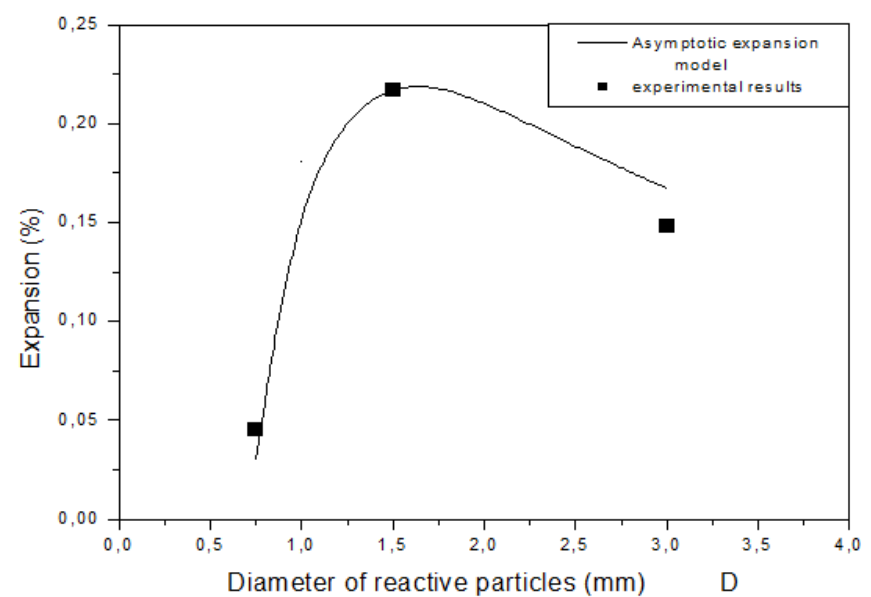

Fig. 6. Expansion of the mortars against the diameter ( $D_{i}$ ) of the reactive particles: Comparison between the experiments and the asymptotic expansion model $(\mathrm{K}=0.1, \mathrm{n}=2.5, \mathrm{x}=0.25, \mathrm{t}=0.7, \mathrm{P}=10 \%)$ 


\section{B. Model calculating the thickness " $t$ " of the porous zone}

As cited in the first section, a porous zone of thickness " $t$ " around the reactive aggregate exists, which is connected to the gel formation site. The volume of porosity to be filled around each particle of diameter $D_{i}$ before the expansion starts was computed according to (6). If this thickness was little, the gel could not move without creating too important pressures on the matrix. Our aim is to estimate this thickness according to the diameter of the reactive particles in order that gel created could be completely adapted by the porosity of the paste.

The volume $V_{i}^{T}$ for the gel created is equal to the sum of the volume of the gel produced by the aggregate during its reaction and of the volume of the porosity in which the gel can diffuse:

$$
V_{i}^{T}=\left[\frac{\pi D_{i}^{3}}{6}-\frac{\pi\left(D_{i}-2 x\right)^{3}}{6}\right]+\left[\frac{\pi\left(D_{i}+2 t\right)^{3}}{6}-\frac{\pi D_{i}^{3}}{6}\right] . P
$$

Then it is necessary that:

$$
V_{i}^{g}=V_{i}^{T}
$$

From (9), the distance " $t$ " is calculated:

$$
t=\frac{\sqrt[3]{\left[\left(\frac{n-1}{P}\right) \cdot\left(D_{i}^{3}-\left(D_{i}-2 x\right)^{3}\right)\right]+D_{i}{ }^{3}}-D_{i}}{2}
$$

The results of calculations using Maple 12 are plotted in Figure 7.

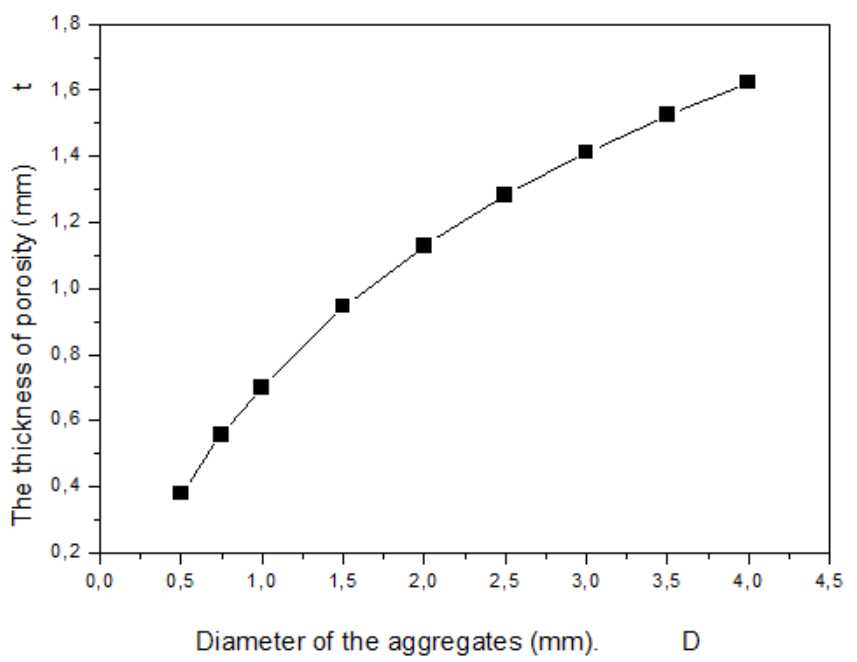

Fig. 7. The distance " $t$ " in which the gel must diffuse in the paste to be completely adapted by the porosity according to the diameter $D_{i}$ of the aggregate ( $n=2.5, x=0.25 \mathrm{~mm}, P=10 \%$ ).

Figure 7 gives the evolution of " $t$ " and shows that the gel produced in the small aggregates $(0.5 \mathrm{~mm})$ needs less distance to be adapted by the porosity of the paste $(t=0.379 \mathrm{~mm})$, however the thickness become important for aggregates greater than $1 \mathrm{~mm}$. The figure shows also that an aggregate greater than $2 \mathrm{~mm}$, for example, needs a thickness of porous zone higher than $1.13 \mathrm{~mm}$ for not generate pressures on the paste. Then, the results of calculations by this model indicates that, if there is a lot of gel, " $t$ " has to be large to prevent expansion for the reactive particles.

\section{CONCLUSION}

In this paper a combination of experiments and modelling was used to study the size effects of the reactive siliceous limestone on AAR-expansions. For this reason, three particle size fractions were studied in mortars and the experimental measurements were presented. The results indicate that, for the (40x40x160) $\mathrm{mm}$ specimen cured in the $1 \mathrm{M} \mathrm{NaOH}$ solution at $80^{\circ} \mathrm{C}$, no AAR-expansion was measured for the mortar bars containing $(0.5-1.0 \mathrm{~mm})$ size range while the mortar bars containing (1.0-2.0 $\mathrm{mm})$ size range show the largest expansion, especially at early ages $(0.217 \%)$ and for bars with (2.0-4.0 $\mathrm{mm})$ aggregate particles, the AAR-expansion measured is $(0.148 \%)$. The first model sums up the main experimental observations; it allows some important phenomena related to the size of reactive aggregate to be interpreted easily. The smallest reactive particles did not cause expansion, but the largest ones expanded greatly. The second model aims to compute the thickness of the porous zone necessary to take back all the volume of the gel created by the reactive aggregates in the cement paste according to the diameter of the grains. The results indicate that the thickness increases with the diameter of the reactive aggregates.

\section{REFERENCES}

[1] B. Capra, A. Sellier, "Orthotropic modeling of alkali-aggregate reaction in concrete structures: numerical simulations”, Mechanics of Materials, Vol. 35, No. 8, pp. 817-830, 2003

[2] A. Sellier, E. Bourdarot, S. Multon, M. Cyr, E. Grimal, “Assessment of the residual expansion for expertise of structures affected by AAR”, 13th International Conference on Alkali-Aggregate Reaction in Concrete, Trondheim, Norway, pp. 1004-1013, 2008

[3] Z. P. Bazant, A. Steffens, "Mathematical model for kinetics of alkali silica reaction in concrete”, Cement and Concrete Research, Vol. 30, No. 3, pp. 419-428, 2000

[4] A. Sellier, J. P. Bournazel, A. Mébarki, "Modelling the alkali aggregate reaction within a probabilistic frame-work", 10th International Conference on Alkali-Aggregate Reaction in Concrete, Melbourne, Australia, pp. 694-701, 1996

[5] S. Poyet, A. Sellier, B. Capra, G. Foray, J. M. Torrenti, H. Cognon, E. Bourdarot, "Chemical modelling of Alkali Silica reaction: influence of the reactive aggregate size distribution”, Materials and Structures, Vol. 40, No. 2, pp. 229-239, 2007

[6] D. McConnell, R. C. Mielenz, W. Y. Holland, K. T. Greene, "Cementaggregate reaction in concrete", Journal of the American Concrete Institute, Vol. 44, No. 2, pp. 93-128, 1947

[7] T. M. Kelly, L. Schuman, F. B. Hornibrook, "A study of alkali-silica reactivity by means of mortar bar expansions", Journal of the American Concrete Institute, Vol. 45, No. 1, pp. 57-80, 1948

[8] S. Diamond, N. Thaulow, "A study of expansion due to alkali-silica reaction as conditioned by the grain size of the reactive aggregate", Cement and Concrete Research, Vol. 4, No. 4, pp. 591-607, 1974

[9] D. W. Hobbs, W. A. Gutteridge, "Particle size of aggregate and its influence upon the expansion caused by the alkali-silica reaction", Magazine of Concrete Research, Vol. 31, No. 109, pp. 235-242, 1979 
[10] M. Kawamura, K. Takemoto, S. Hasaba, “Application of quantitative EDXA analyses and microhardness measurements to the study of alkalisilica reaction mechanisms", 6th International Conference of Alkalis in Concrete, Copenhague, Denmark, pp. 167-174, 1983

[11] R. E. Oberholster, G. Davies, “An accelerated method for testing the potential alkali reactivity of siliceous aggregates”, Cement and Concrete Research, Vol. 16, No. 2, pp.181-89, 1986

[12] D. Lu, B. Fournier, P. E. Grattan-Bellew, "Evaluation of accelerated test methods for determining alkali-silica reactivity of concrete aggregates", Cement and Concrete Composites, Vol. 28, No. 6, pp. 546-554, 2006

[13] S. Multon, M. Cyr, A. Sellier, P. Diederich, L. Petit, "Effects of aggregate size and alkali content on ASR expansion”, Cement and Concrete Research, Vol. 40, No. 4, pp. 508-516, 2010

[14] M. Moissan, "Contribution to the mastery of alkali silica reaction by adding fine reactive aggregates in concrete”, Doctoral thesis, Toulouse, 2005 ("Contribution à la maitrise de la réaction alcali silice par ajout de fines de granulats réactifs dans le béton”, Thèse de doctorat, Toulouse, 2005)

[15] L. S. Dent-Glasser, N. Kataoka, "The chemistry of alkali-aggregate reaction", 5th International Conference on Alkali-Aggregate Reaction in concrete, Cape Town, South Africa, 1981.

[16] S. Chatterji, N. Thaulow, "Some fundamentals of alkali-silica reaction", 11th International Conference on Alkali-Aggregate Reaction in Concrete, Québec City, Québec, pp. 21-29, 2000

[17] H. Wang, J. E. Gillott, "Mechanism of alkali-silica reaction and the significance of calcium hydroxide", Cement and Concrete Research, Vol. 21, No. 4, pp. 647-654, 1991

[18] S. Poyet, "Study of the degradation of concrete structures affected by alkali-silica reaction: Experimental approach and multi-scale numerical modeling of damage in an environment variable hydro-chemomechanical”, Doctoral thesis, University of Marne-La-Vallée, 2003. ("Etude de la dégradation des ouvrages en béton atteints par la réaction alcali-silice : Approche expérimentale et modélisation numérique multiéchelles des dégradations dans un environnement hydro-chemomécanique variable”, Thèse de doctorat, Université de Marne-La-Vallée, 2003)

[19] C. F. Dunant, K. L. Scrivener, "Effects of aggregate size on alkalisilica-reaction induced expansion”, Cement and Concrete Research, Vol. 42, No. 6, pp. 745-751, 2012 